\title{
Smart Shoppe Trolley
}

\author{
R.Balamurugan ${ }^{1}$, N.R.Nagarajan ${ }^{2}$ \\ Assistant professor, ECE, K.Ramakrishnan College of Engineering, Trichy, India ${ }^{1,2}$
}

\begin{abstract}
The Automated Shopping trolley is an innovative consumer purchasing product that is designed to help shopper's fast-track their shopping experience. This dramatically reduces shopping and checkout time. The RFID reader is placed on the trolley and the RFID tag will be placed on the products. The RFID tag has the individual unique ID for every products. So consumer can select the particular products without any error, if the RFID reader senses the particular product, it sends the signals to the PIC micro controller, which is used to read and count the product information and displays the total bill amount. It uses the ultrasonic sensor and IR sensors to follow the consumer like human follower, The IR obstacle sensor is used to senses the obstacle in supermarket while moving. If the load exceeds the threshold weight, the overload message is displayed and the buzzer sound is hear. The various sections of shopping mall is displayed in the LCD interfaced with the micro controller. It reduces the precious time of the consumer unnecessarily standing in the queue for billing \&payment.
\end{abstract}

Keywords: RFID, Smart Shopping, Trolley, Human Follower, PIC Micro Controller

\section{INTRODUCTION}

Shopping mall is a place where most people from all walks of life will get their daily necessities ranging from food product, apparels, toiletries; gardening tools electrical appliances, and others. The numbers of small and large shopping malls keep on increasing over the years throughout the globe due to the demand of the public. Thus, the level of advancement of shopping mall system and infrastructure also varies. Compared to some foreign countries' shopping mall system, there are still a plenty of spaces for improvement in terms of providing quality shopping experience to the consumers. Consumers often face many problems and inconvenience when shopping. These problems include worrying that the amount of money brought is not enough for paying all the items needed, insufficient information of the items that are for sale and also wasting time at the cashier by standing in queue for billing. Difficulty in pushing the trolley due to its weight. These are the problems that are currently faced by most consumers. The smart shoppe trolley is the automated human follower and Automatized shopping method using Radio Frequency Identification system. It displays the bill amount, and weight of the products, and indicates the various sections of the shopping mall like section 1kitchen products, section 2 - children section, section 3-stationary products etc.

\section{EXISTING SYSTEM}

Electronic Shopping is equipped with Barcode Scanner for product identification and a consistent Wi-Fi connection with the shop's server. Besides, it also has an LCD display that informs customers about produt prices, and the total bill. The barcode reader identifies the product and updates the bill. When the customer is done with shopping, he can just press the End shopping button and the details are sent to the shop's server and the customer has to pay just the amount and leave. This has the following disadvantages, Can't be read for a distance of more than 4 inches, Unreliable, high cost, Barcode lacks read and write facility.

\section{PROPOSED SYSTEM}

The proposed system for the design of Smart Shoppe Trolley with the block diagram shown in the Fig 1.The hardware component includes Power supply(5V), IR obstacle sensor, ultrasonic sensor, RFID tag, RFID reader, Driver, Relay, Motor, LCD display, Buzzer, Load cell, switches. The software used here is MPLab IDE. An alternative to barcode system is the Radio Frequency Identification(RFID) which is highly preferable method. A radio-frequency identification system uses tags, or labels attached to the objects to be identified. The Two-way radio transmitter receiver called interrogators or readers send a signal to the tag and read its response. A Radio Frequency Identification Tag (RFID tag) is an electronic tag that exchanges data with a RFID reader through radio waves. Most RFID tags are made up of at least two main parts. The first is an an antenna, which receives radio frequency (RF) waves. The second is an integrated circuit (IC), which is used for processing and storing data, as well as modulating and demodulating the radio waves received/sent by the antenna. RFID is a technology similar in theory to bar codes. However, the RFID tag does not have to be scanned directly, nor does it require line-of- sight to a reader. In order to overcome the major issue of searching products in shop, in our project the RFID is placed on the trolley, and the RFID tag will be placed on the products. So 
Vol. 8, Issue 5, May 2019

that we can search and select the products by using this RFID system. The RFID tag has the individual unique ID for every products. So we can select the particular products without any error. If the RFID reader senses the particular product, it will sends the signals to the PIC micro controller, which is used to read \& count the product information and send these information to microcontroller and displayed in the LCD. ULTRASONIC sensor uses SONAR to determine distance of an object and thus by sensing the movement of the consumer the trolley follows the consumer. IR obstacle sensor is used to detect the obstacle while moving and thus by sensing

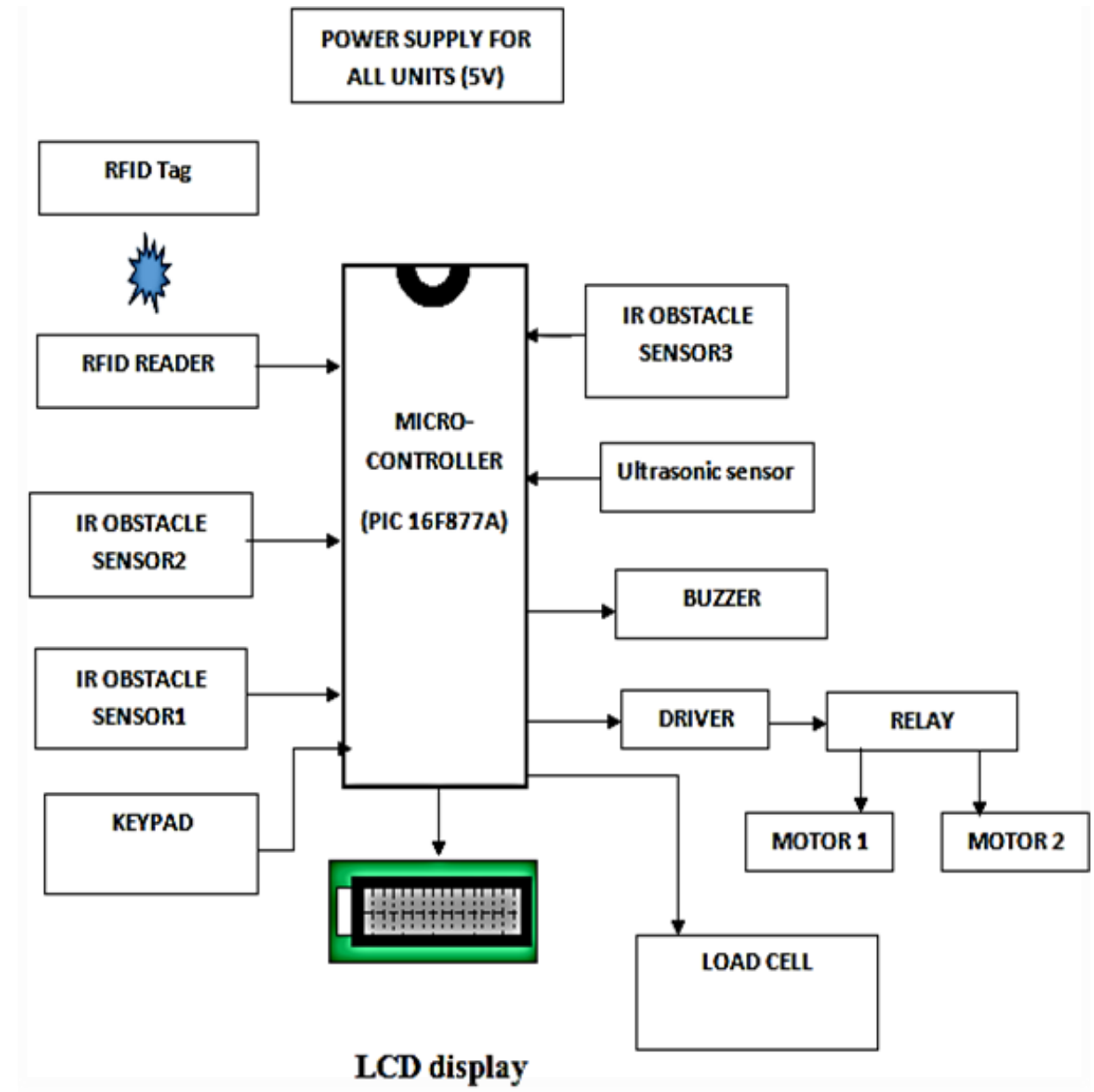

Fig. 1 Block Diagram of the Smart shoppe trolley

\section{RESULTS \& DISCUSSIONS}

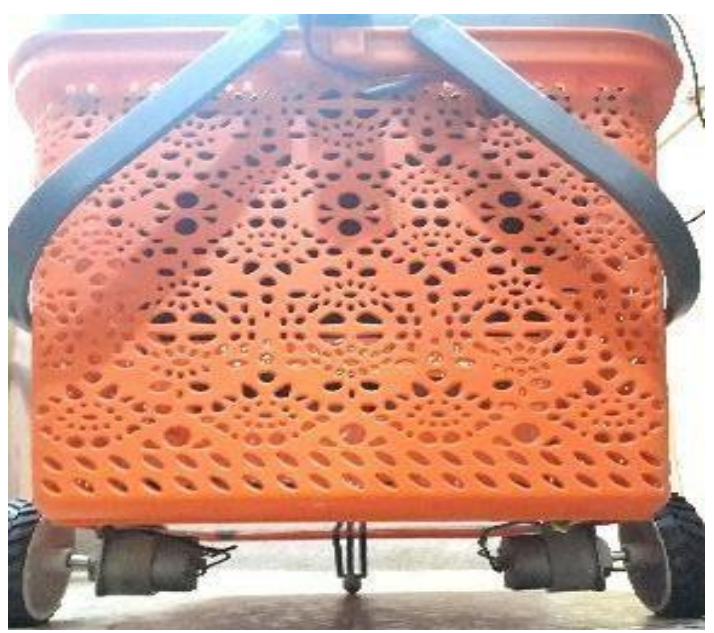

Fig 2. Trolley Back View 
Vol. 8, Issue 5, May 2019

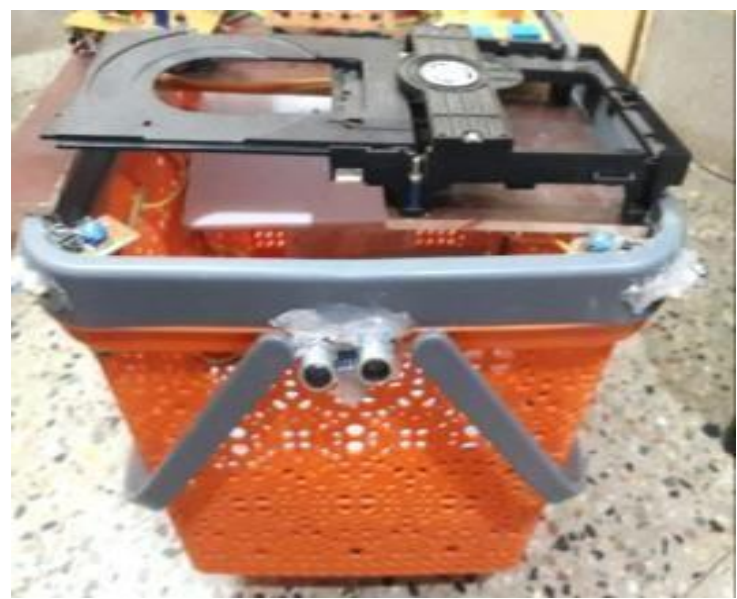

Fig 3. Trolley Front View

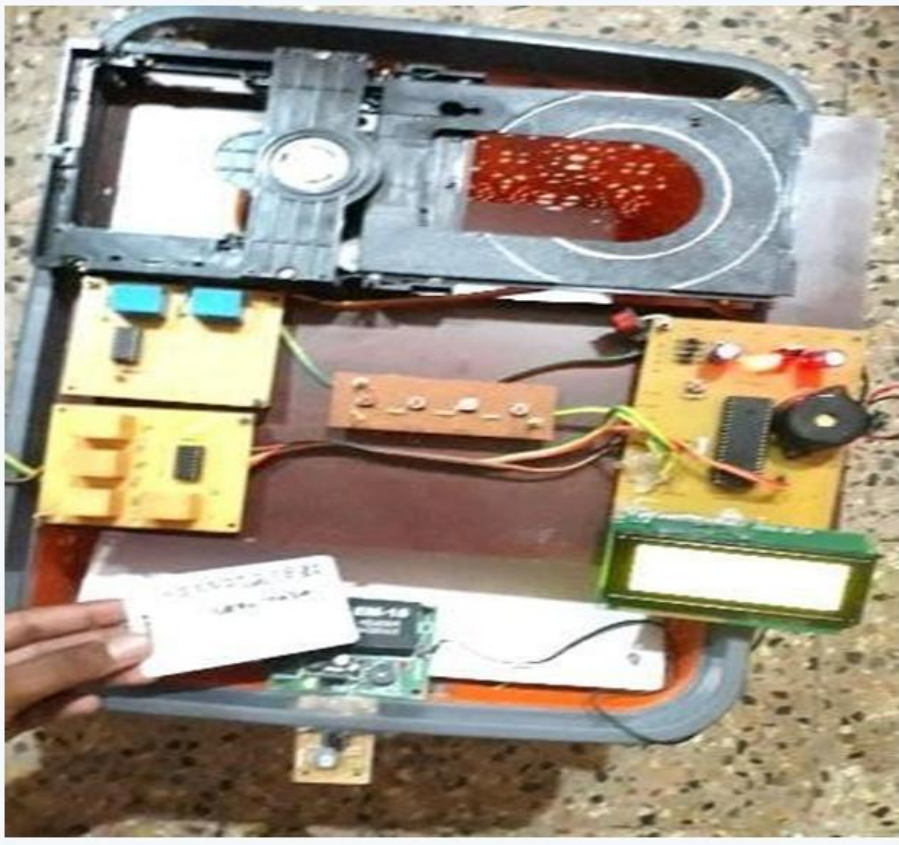

Fig 4. Trolley Top View

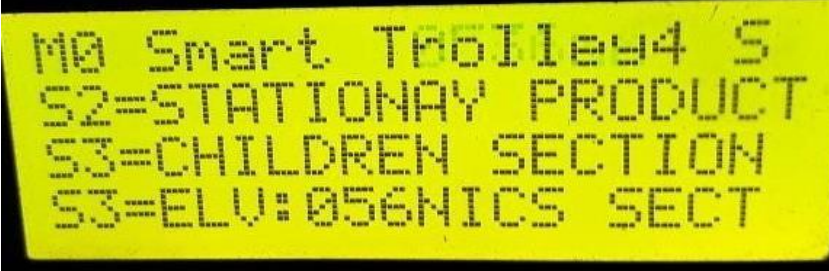

Fig 5. Display indication of various sections of shopping mall

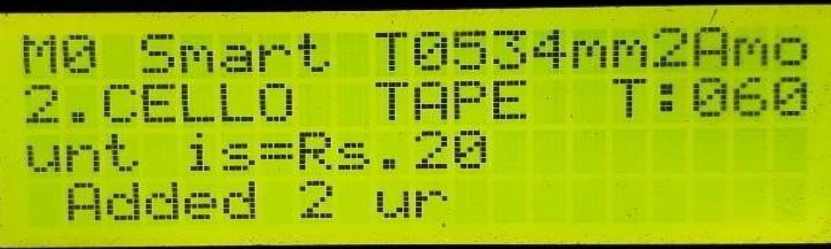

Fig 6. Display indication of product details 
Vol. 8, Issue 5, May 2019

Hence the Smart Shoppe trolley is seen in back view, front view, top view as shown in the figure 2 , figure 3 \&figure 4 respectively. The Smart Shoppe trolley is designed by DC motor placed at the wheels of the trolley by using the relay and the driver circuit. It can easily move with the consumer with the help of IR sensors. The ultrasonic sensor is used to measure the distance between the human and the trolley. The IR obstacle sensors are used to detect the object while moving, and to make the trolley turn right and left along with the human movement. The various sections in the shopping mall is displayed in the LCD from the Fig5, it easily helps the consumer to identify the products. The trolley wheels were the interfacing of DC motors and the sensors to the microcontroller PIC16F877A for necessary movements.

\section{CONCLUSION}

The proposed method overcomes the shortcomings of existing method. Rewriting is also possible in RFID which lacks in the existing methodology. This makes our shopping experience faster and good and also useful for disabled peoples, senior citizens, and consumers to shop easily. This method overcomes the difficulty of pushing the trolley, reduces manpower required in billing section. This can reduce the expenses incurred by the management. Users can be aware of the total bill amount during the time of purchase. Increases consumer satisfaction. Guides/directs the customer to the product and reduces the theft in the shopping supermarket time spent at billing counter.

\section{REFERENCES}

[1]. Y.J.Zuo "Survivable RFID system: Issue, challenges, techniques", IEEE Trans. Syst, Man, Cybern. C, Appl.Rev., vol.40, no.4, pp.406-418 2010.

[2]. F. Gandino , B. Montrucchio, M. Rebaudengo and E. R. Sanchez "On improving automation by integrating RFID in the traceability management of the agri-food sector", IEEE Trans. Ind. Electron., vol. 56, no. 7, pp.2357 -2365 2009

[3]. T.M.Choi "Coordination \& risk analysis of VMI supply chains with RFID technology", IEEE Trans Ind. Informat., vol.7, no.3, pp.497-504 2011

[4]. R.Balamurugan, N.R.Nagarajan “Automatic Robotic Arm Using Hand Gestures”, International journal of Engineering Research \& Technology. Issn: 2278 - 0181 march 2017.

[5]. R.Balamurugan, N.R.Nagarajan "Smart Method Of Vehicular Tactical Manoeuvre system" International Journal of Advanced Research in Electrical Electronics and Instrumental Engineering volume 8issue 4 April 2019. ISSN 2320-3765

[6]. N.R.Nagarajan, R.Balamurugan, "A DFT Tactic Aimed at Testable Q-flop Rudiments", International Journal of Advanced Research in Electrical Electronics and Instrumental Engineering volume 8issue 4 April 2019. ISSN 2320-3765

[7]. J. D. Porter and D. S. Kim "An RFID- enabled road pricing system for transportation", IEEE Syst. J., vol. 2, no. 2, pp.248 -257 2008

[8]. H. H. Bi and D. K. Lin "RFID-enabled discovery of supply networks", IEEE Trans. Eng. Manag., vol. 56, no. 1, pp.129 -141 2009

[9]. K. Finkenzeller RFID Handbook: Fundamentals and Applications in Contactless Smart Cards and Identification, 2003 :Wiley

[10]. J. Z. Gao , L. Prakash and R. Jagatesan "Understanding 2D-BarCode technology and application in M-commerce-design and implementation of a 2D barcode processing solution", Proc. Comput. Softw. Appl. Conf., pp.49 -56 2007

[11]. D. Hahnel , W. Burgard , D. Fox , K. Fishkin and M. Philipose "Mapping and localization with RFID technology", Proc. IEEE Int. Conf Robot. Autom., pp.1015 - 10202004

[12]. J. Y. Zhou , J. Shi and X. L. Qiu "Landmark placement for wireless localization in rectangular-shaped industrial facilities", IEEE Trans. Veh. Technol., vol. 59, no. 6, pp.3081 -3090 2010

\section{BIOGRAPHIES}

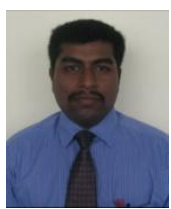

R.Balamurugan, completed Bachelors degree in Electronics and Communication Engineering and Masters VLSI Design from Anna University in 2008 and 2012 respectively. He is lifetime Member of Indian Society of Technical Education (MISTE), and field of research interest is designing Realtime Embedded Systems, IOT, Wireless Communication. He has a teaching experience of 8 years. Presently working as Assistant Professor, ECE Dept. in K. Ramakrishnan College Of Engineering, Trichy.

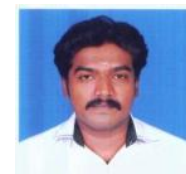

Mr. N. R. Nagarajan, completed his Bachelor of Engineering under the stream of Electronics and Communication Engineering and Masters in VLSI Desing from Anna University, Chennai in 2010 and 2012 respectively. Currently pursuing his Ph.D in the field of SoC field of 5G.He is a life time member of Indian Society of Technical Education (MISTE), and his field of research interests are VLSI Design, Signals and Systems, SoC, NoC, 5G Architecture, Millimeter Wave Communication, Space Time Wireless Communication. He has a teaching experience of 7 years and currently working as Assistant Professor in the Department of ECE at K. Ramakrishnan College of Engineering, Samayapuram, Trichy. 